\title{
Solidification properties and microstructure investigation of the as-cast Sn-rich alloys of the Sn-Sb-Zn ternary system
}

\author{
S. Mladenović*, D. Manasijević, B. Maluckov, I. Marković, S. Marjanović, D. Živković \\ University of Belgrade, Technical Faculty, VJ 12, 19210 Bor, Serbia
}

Received 1 April 2014, received in revised form 9 June 2015, accepted 23 June 2015

\begin{abstract}
Solidification properties and microstructure of six as-cast Sn-Sb-Zn alloys with 80 at.\% of $\mathrm{Sn}$ and variable contents of $\mathrm{Sb}$ and $\mathrm{Zn}$ were experimentally investigated using scanning electron microscopy (SEM) with energy dispersive microanalysis (EDS) and differential thermal analysis (DTA). Experimentally obtained results were compared with predicted phase equilibria according to the calculation of phase diagram (CALPHAD) method and with Scheil solidification simulation. An electrical conductivity measurement of investigated alloys was also performed.
\end{abstract}

K e y w ord s: Sn-Sb-Zn system, solidification, differential thermal analysis, electrical conductivity

\section{Introduction}

Electronic devices are operating faster and becoming smaller, lighter and more functional and for these reasons, advanced packaging technology is required. Many advanced packaging technologies have been developed. The multi-chip module (MCM) is a group of highly functional electronic devices interconnected to the substrate. When integrated circuit chips are packaged in MCM, step soldering is used.

Step soldering refers to a process in which soldering is applied more than once in different stages during the manufacturing. To avoid remelting of the earlier solder joints in the later soldering processes, solders with different melting points are used [1].

The $95 \mathrm{~Pb}-5 \mathrm{Sn}$ solder with a melting temperature of $308-312^{\circ} \mathrm{C}$ is used for high-temperature applications in step soldering [2]. Due to environmental concerns the use of $\mathrm{Pb}$ is restricted and new $\mathrm{Pb}$-free high-temperature solder alloys are required.

Several studies of $\mathrm{Pb}$-free high-temperature solder alloys have been performed [3-6]. It was concluded that among various lead-free solders, Sn-Sb based alloys are promising candidates for the replacement of the high-melting-point Sn-95 wt.\% Pb alloy [3-6]. In those studies authors investigated the phase diagram, melting behavior, electrical resistivity, wettability, viscosity and mechanical properties of Sn-Sb alloys.

Since the properties of the binary $\mathrm{Pb}$-free solders cannot fully meet the requirements for applications in electronic packaging, additional alloying elements were added to improve the performance of these alloys [7]. Hence, ternary Sn-Sb-Zn alloys may also be considered as promising lead-free solders. To our best knowledge, a small number of studies on the Sn-Sb-Zn ternary alloys have been published. Gancarz and Gasior [8] performed the electromotive force measurement to obtain zinc activity in liquid $\mathrm{Sn}-\mathrm{Sb}-\mathrm{Zn}$ alloys. Phase transition temperatures and compositions of coexisting phases after long-term annealing at 200, 250 and $350^{\circ} \mathrm{C}$ have been determined by Zobac et al. [9]. Stability of one ternary phase with the chemical composition corresponding to the $\mathrm{Sb}_{2} \mathrm{SnZn}$ compound in some of the investigated samples has been experimentally determined [9].

In this study, microstructure and composition of coexisting phases in the investigated as-cast Sn-rich alloys of the Sn-Sb-Zn system were experimentally determined using SEM-EDS analysis and compared with the thermodynamically predicted phase equilibria based on the 4.4 SGTE values of Gibbs energies for pure elements [10] and thermodynamic binary data 
included in the COST 531 thermodynamic database [11]. Phase transition temperatures of the investigated alloys were measured using DTA technique and also compared with the results of thermodynamic prediction. Taking into consideration the possible applications of investigated samples, we broadened our study with measurements of samples' electrical conductivities.

\section{Experimental procedure}

Six ternary alloys, with the constant atomic percent of $\mathrm{Sn}$ (80 at.\%) and variable contents of $\mathrm{Zn}$ and $\mathrm{Sb}$ were prepared using Sn, Zn, and Sb (purity 99.99\%) as starting materials.

The appropriate weights of the elements were melted in an induction furnace under an argon atmosphere. The alloys were melted several times to improve homogeneity. The molten solders in crucible were chill cast in a graphite mold to form cylindrical ingots of $17 \mathrm{~mm}$ in diameter. As-cast alloys were obtained by cooling in air.

To observe the microstructure of the six as-cast solder alloys, the specimens were polished with $0.05 \mu \mathrm{m}$ $\mathrm{Al}_{2} \mathrm{O}_{3}$ powders and etched with $2 \% \mathrm{HCl}, 3 \% \mathrm{HNO}_{3}$ and $95 \%$ (vol.\%) $\mathrm{C}_{2} \mathrm{H}_{5} \mathrm{OH}$ solution for a few seconds.

The overall compositions and compositions of the present phases in the as-cast specimens were examined by Scanning Electron Microscopy using JEOL (JSM6460) microscope equipped with Oxford Instruments Energy Dispersive Spectrometer.

Differential thermal analysis (DTA) experiments were carried out using a laboratory-made DTA apparatus with the thermocouples inserted directly into the sample and inert reference material under following conditions: flowing argon atmosphere, sample masses about $2 \mathrm{~g}$, and alumina as the reference material. A heating rate of $5^{\circ} \mathrm{C} \mathrm{min}^{-1}$ was employed both for calibration and measurement of the prepared samples. The data were collected using the personal computer.

Electrical conductivity measurements were carried out using Foerster SIGMATEST 2.069 eddy current instrument.

\section{Theoretical basis}

Phase equilibria calculations were performed using CALPHAD (CALculation of PHase Diagram) method [12]. CALPHAD approach is based on a calculation of the Gibbs energy of a phase as a function of its composition, temperature, and pressure. Gibbs energy data for all phases appearing in the investigated system should be stored as polynomial functions in the thermodynamic database. Once this is accomplished, calculation of phase equilibria is done using constrained minimization of system's Gibbs energy method [12]. There are several software packages available for CALPHAD-type calculations of phase equilibria like Thermo-Calc [13] and PANDAT [14]. In this study PANDAT 8.1. software was used.

\section{Results and discussion}

\subsection{Thermodynamic prediction of the phase equilibria and Scheil solidification simulation}

For a better understanding of the obtained experimental results, equilibrium phase diagram of the investigated ternary $\mathrm{Sn}-\mathrm{Sb}-\mathrm{Zn}$ system was extrapolated using optimized thermodynamic parameters for the constitutive binary systems included in the COST 531 database [11]. The ternary phase $\mathrm{Sb}_{2} \mathrm{SnZn}$ found in ref. [9] was not taken into calculation procedure.

Table 1. Considered phases, phase names in the thermodynamic database and Pearson's symbols

\begin{tabular}{lcc}
\hline Thermodynamic database name & Phase common names & Pearson's symbol \\
\hline LIQUID & Liquid & $h R 2$ \\
RHOMBO_A7 & $(\mathrm{Sb})$ & $h P 2$ \\
HCP_ZN & $(\mathrm{Zn})$ & $o P 16$ \\
SBZN_BETA & $\beta$ & - \\
SBZN_GAMMA & $\gamma$ & - \\
SBZN_DELTA & $\delta$ & - \\
SBZN_EPSILON & $\varepsilon$ & $o I^{*}$ \\
SBZN_ZETA & $\zeta$ & oP30 \\
SBZN_ETA & $\eta$ & $C F 8$ \\
BCT_A5 & $(\beta \mathrm{Sn})$ & $c F 8$ \\
DIAMOND_A4 & $(\alpha \mathrm{Sn})$ & - \\
SBSN & $\mathrm{SbSn}$ & \\
SB2SN3 & $\mathrm{Sb}_{2} \mathrm{Sn} n_{3}$ & \\
\hline
\end{tabular}



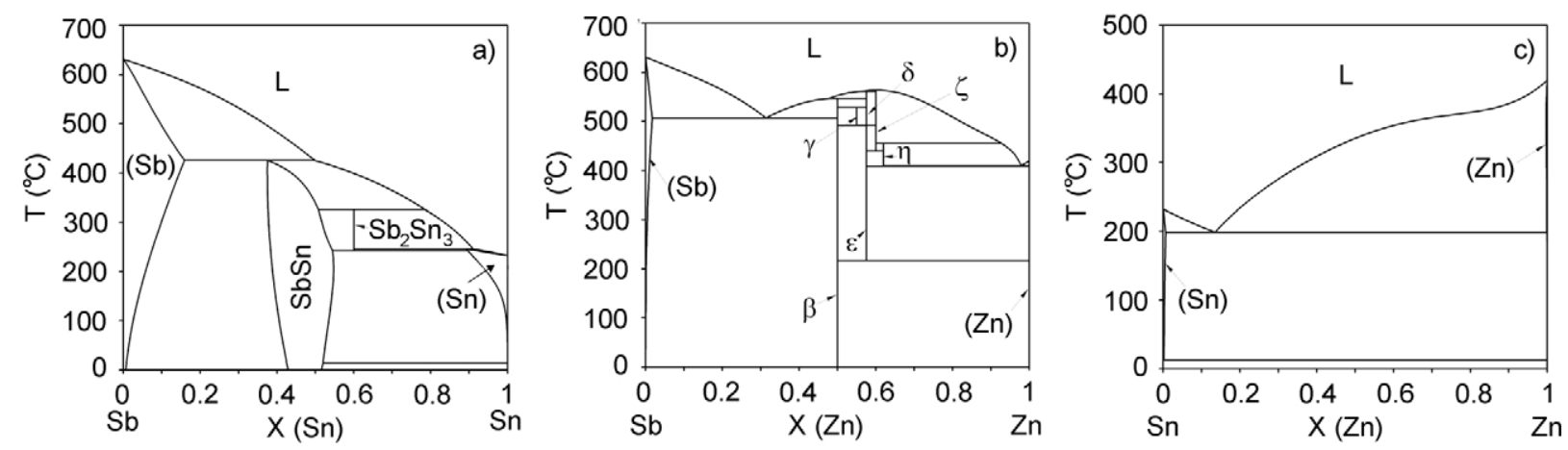

Fig. 1. Equilibrium phase diagrams of the constitutive binary systems calculated using optimized thermodynamic parameters from the COST 531 database [11]: (a) Sb-Sn system; (b) Sb-Zn system; (c) Sn-Zn system.

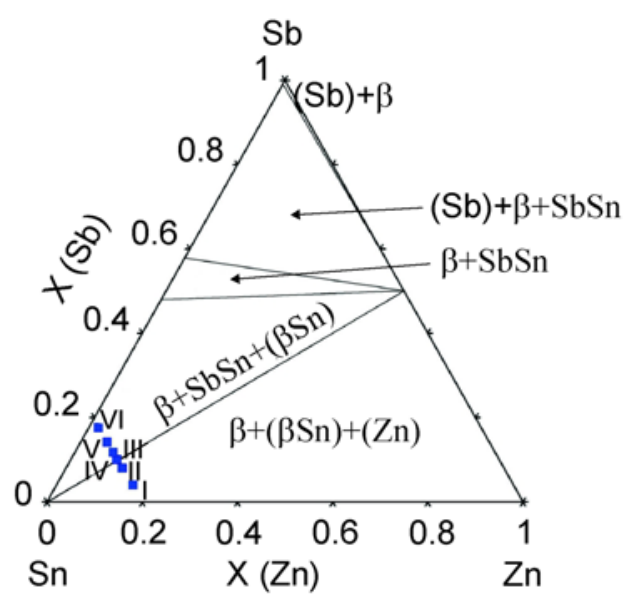

Fig. 2. Thermodynamically predicted equilibrium phase diagram of the ternary $\mathrm{Sn}-\mathrm{Sb}-\mathrm{Zn}$ system at $25^{\circ} \mathrm{C}$ with marked overall compositions of the investigated alloy samples.

Names of the phases from constitutive binary subsystems considered in the calculation with their related names from the COST 531 database and corresponding Pearson's symbols [15] are listed in Table 1.

Calculated phase diagrams of the Sb-Sn, Sb-Zn and Sn-Zn binary systems with marked existing phases are given in Fig. 1.

To predict possible coexisting phases in investigated samples of the Sn-Sb-Zn ternary system in equilibrium conditions at room temperature, an isothermal section of the Sn-Sb-Zn ternary system at $25^{\circ} \mathrm{C}$ was calculated and shown in Fig. 2 together with overall compositions of the investigated samples in this study.

There are totally five phase fields observed in Fig. 2: $(\beta+(\beta \mathrm{Sn})+(\mathrm{SbSn})),(\beta+(\mathrm{SbSn})),(\beta+$ $(\beta \mathrm{Sn})+(\mathrm{Zn})),((\mathrm{Sb})+\beta+(\mathrm{SbSn}))$, and $((\mathrm{Sb})+\beta)$.

According to the results of thermodynamic prediction, in equilibrium conditions, overall compositions of the samples I, II belong to the $(\beta+(\mathrm{Sn})+(\mathrm{Zn}))$ three- -phase field, while overall compositions of the samples III, IV, V, and VI belong to the $(\beta+(\mathrm{SbSn})+(\mathrm{Sn}))$ three-phase field.

Having in mind that in this study alloys of the $\mathrm{Sn}-\mathrm{Sb}-\mathrm{Zn}$ ternary system were investigated in the as-cast state (fast cooling rate) it is valuable to, beside equilibrium calculation, perform a simulation of non-equilibrium solidification according to Scheil model for comparison. Figure 3 shows Scheil solidification simulation curves with marked phase transition temperatures for all six investigated samples.

The results obtained by Scheil non-equilibrium solidification for investigated samples $\mathrm{I}$ to $\mathrm{V}$ indicate that solidification of these alloys begins with the formation of primary $\beta$ phase. For the sample VI, primary solidification phase is $\mathrm{Sb}_{2} \mathrm{Sn}_{3}$ compound. With further cooling in the samples I, II and III simultaneous crystallization of $\beta$ and (Sn) phases occurs in mono variant temperature region. At invariant temperature, the rest of the liquid phase solidifies due to the occurrence of ternary eutectic reaction $\mathrm{L} \leftrightarrow \beta+$ $(\mathrm{Sn})+(\mathrm{Zn})$ at calculated temperature $198^{\circ} \mathrm{C}$.

Solidification simulation for the samples V and VI, beside above given ternary eutectic reaction, predicts the occurrence of two ternary peritectic reactions, i.e. transition reactions: $\mathrm{L}+\mathrm{SbSn} \leftrightarrow \beta+\mathrm{Sb}_{2} \mathrm{Sn}_{3}$ at $248^{\circ} \mathrm{C}$ and $\mathrm{L}+\mathrm{SbSn} \leftrightarrow \beta+(\mathrm{Sn})$ at $238^{\circ} \mathrm{C}$.

\subsection{Microstructure investigation}

Microstructure investigation of samples was performed using SEM-EDS analysis. Energy dispersive spectrometer analysis (EDS) was used to determine overall chemical compositions of the investigated samples and for determination of chemical compositions of coexisting phases.

Results of SEM-EDS analysis in comparison with results of thermodynamic binary-based prediction of phase equilibria are given in Table 2 .

SEM micrographs for the samples I, III and VI are presented in Fig. 4 as examples. Qualitative agreement between experimentally obtained phase struc- 

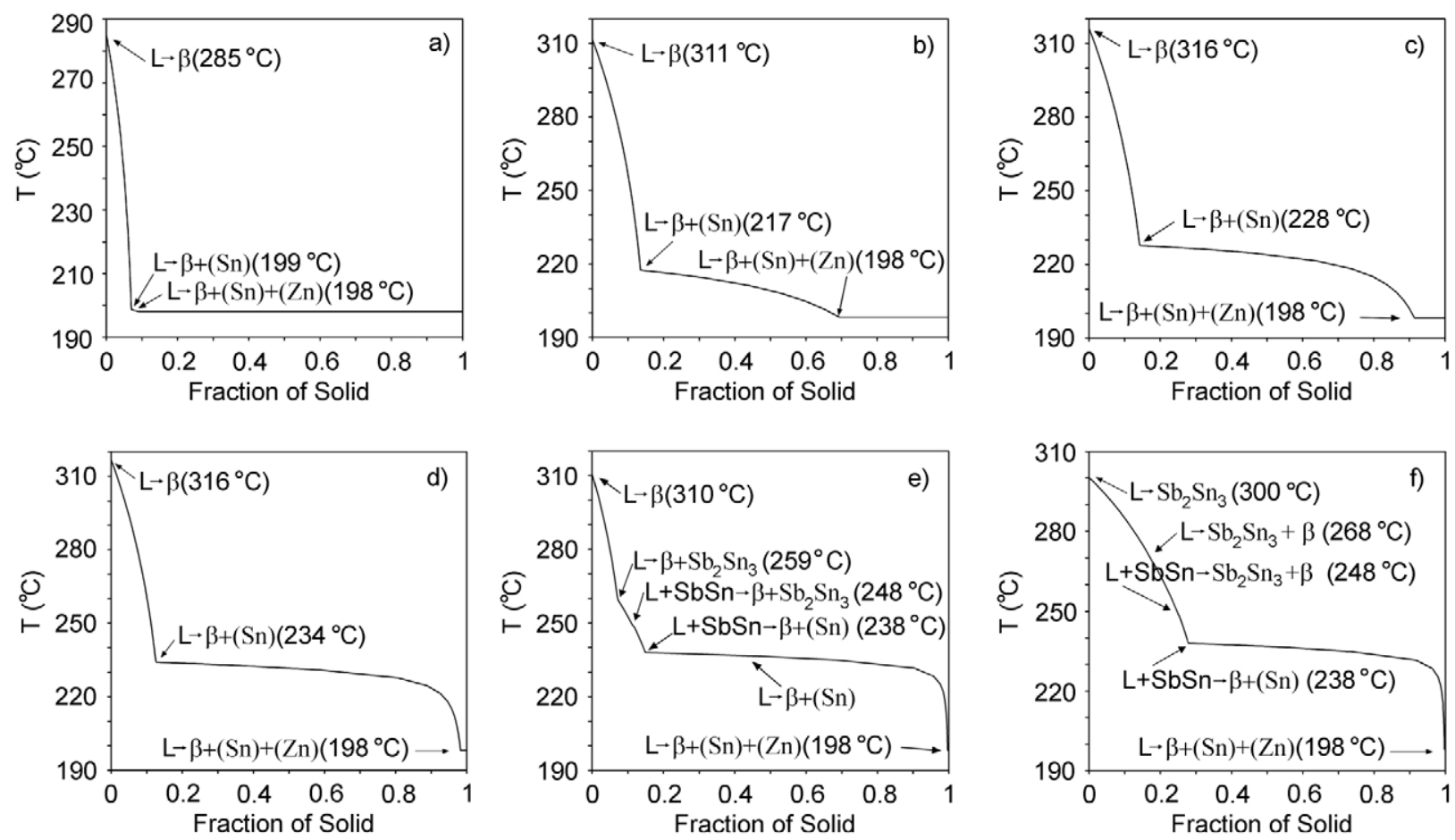

Fig. 3. The Scheil solidification simulation for the sample: a) I $\left(\mathrm{Sb}_{3.97} \mathrm{Sn}_{80.08} \mathrm{Zn}_{15.95}\right)$; b) II $\left(\mathrm{Sb}_{7.97} \mathrm{Sn}_{80.31} \mathrm{Zn}_{11.72}\right)$; c) III $\left(\mathrm{Sb}_{10.04} \mathrm{Sn}_{80.39} \mathrm{Zn}_{9.57}\right)$; d) IV ( $\left.\mathrm{Sb}_{11.70} \mathrm{Sn}_{80.37} \mathrm{Zn}_{7.93}\right)$; e) V(Sb14.13 $\left.\mathrm{Sn}_{80.38} \mathrm{Zn}_{5.49}\right)$; f) VI ( $\left.\mathrm{Sb}_{17.57} \mathrm{Sn}_{80.52} \mathrm{Zn}_{1.91}\right)$. Composition in at.\%.

Table 2. Experimentally determined overall and phase compositions of the investigated as-cast alloys of the ternary $\mathrm{Sn}-\mathrm{Sb}-\mathrm{Zn}$ system in comparison with thermodynamically predicted equilibrium phases at $25^{\circ} \mathrm{C}$

\begin{tabular}{|c|c|c|c|c|c|c|c|c|c|}
\hline \multirow{2}{*}{ Alloy } & \multirow{2}{*}{$\begin{array}{c}\text { Sample } \\
\text { composition } \\
\text { (at.\%) }\end{array}$} & \multirow{2}{*}{$\begin{array}{c}\text { Experiment. } \\
\text { determined } \\
\text { phases }\end{array}$} & \multirow{2}{*}{$\begin{array}{l}\text { Theoret. } \\
\text { predict. } \\
\text { phases }\end{array}$} & \multicolumn{2}{|c|}{ Sn (at.\%) } & \multicolumn{2}{|c|}{$\mathrm{Sb}(\mathrm{at} . \%)$} & \multicolumn{2}{|c|}{ Zn (at.\%) } \\
\hline & & & & exp. & calc. & exp. & calc. & exp. & calc. \\
\hline \multirow[t]{3}{*}{ I } & $\mathrm{Sn}=80.08$ & $\beta$ & $\beta$ & 1.24 & - & 51.64 & 50.00 & 47.12 & 50.00 \\
\hline & $\mathrm{Sb}=3.97$ & $(\mathrm{Sn})$ & $(\mathrm{Sn})$ & 91.80 & 100.00 & 0.46 & - & 7.74 & - \\
\hline & $\mathrm{Zn}=15.95$ & (Zn) & $(\mathrm{Zn})$ & 1.23 & - & - & - & 98.77 & 100.00 \\
\hline \multirow[t]{3}{*}{ II } & $\mathrm{Sn}=80.31$ & $\beta$ & $\beta$ & 2.49 & - & 50.59 & 50.00 & 46.92 & 50.00 \\
\hline & $\mathrm{Sb}=7.97$ & $(\mathrm{Sn})$ & $(\mathrm{Sn})$ & 94.93 & 100.00 & 2.58 & - & 2.49 & - \\
\hline & $\mathrm{Zn}=11.72$ & (Zn) & $(\mathrm{Zn})$ & 0.95 & - & - & - & 99.05 & 100.00 \\
\hline \multirow[t]{3}{*}{ III } & $\mathrm{Sn}=80.39$ & $\mathrm{Sb}_{5} \mathrm{Sn}_{3} \mathrm{Zn}_{2}$ & $\beta$ & 29.57 & - & 51.57 & 50.00 & 18.86 & 50.00 \\
\hline & $\mathrm{Sb}=10.04$ & $(\mathrm{Sn})$ & $(\mathrm{Sn})$ & 93.98 & 100.00 & 4.17 & - & 1.85 & - \\
\hline & $\mathrm{Zn}=9.57$ & & SbSn & - & 52.12 & & 47.88 & - & - \\
\hline \multirow[t]{3}{*}{ IV } & $\mathrm{Sn}=80.37$ & $\mathrm{Sb}_{5} \mathrm{Sn}_{3} \mathrm{Zn}_{2}$ & $\beta$ & 29.86 & - & 51.91 & 50.00 & 18.23 & 50.00 \\
\hline & $\mathrm{Sb}=11.70$ & $(\mathrm{Sn})$ & $(\mathrm{Sn})$ & 93.98 & 100.00 & 4.34 & - & 1.68 & - \\
\hline & $\mathrm{Zn}=7.93$ & - & $\mathrm{SbSn}$ & - & 52.12 & & 47.88 & & - \\
\hline \multirow[t]{3}{*}{$\mathrm{V}$} & $\mathrm{Sn}=80.38$ & $\mathrm{Sb}_{5} \mathrm{Sn}_{3} \mathrm{Zn}_{2}$ & $\beta$ & 30.06 & - & 52.06 & 50.00 & 17.88 & 50.00 \\
\hline & $\mathrm{Sb}=14.13$ & $(\mathrm{Sn})$ & $(\mathrm{Sn})$ & 92.64 & 100.00 & 6.70 & - & 0.66 & - \\
\hline & $\mathrm{Zn}=5.49$ & & $\mathrm{SbSn}$ & - & 52.12 & & 47.88 & - & - \\
\hline \multirow[t]{3}{*}{ VI } & $\mathrm{Sn}=80.52$ & $\mathrm{Sb}_{5} \mathrm{Sn}_{3} \mathrm{Zn}_{2}$ & $\beta$ & 30.41 & - & 51.82 & 50.00 & 17.77 & 50.00 \\
\hline & $\mathrm{Sb}=17.57$ & $(\mathrm{Sn})$ & $(\mathrm{Sn})$ & 91.84 & 100.00 & 7.28 & - & 0.88 & - \\
\hline & $\mathrm{Zn}=1.91$ & SbSn & $\mathrm{SbSn}$ & 55.56 & 52.12 & 44.03 & 47.88 & 0.41 & - \\
\hline
\end{tabular}



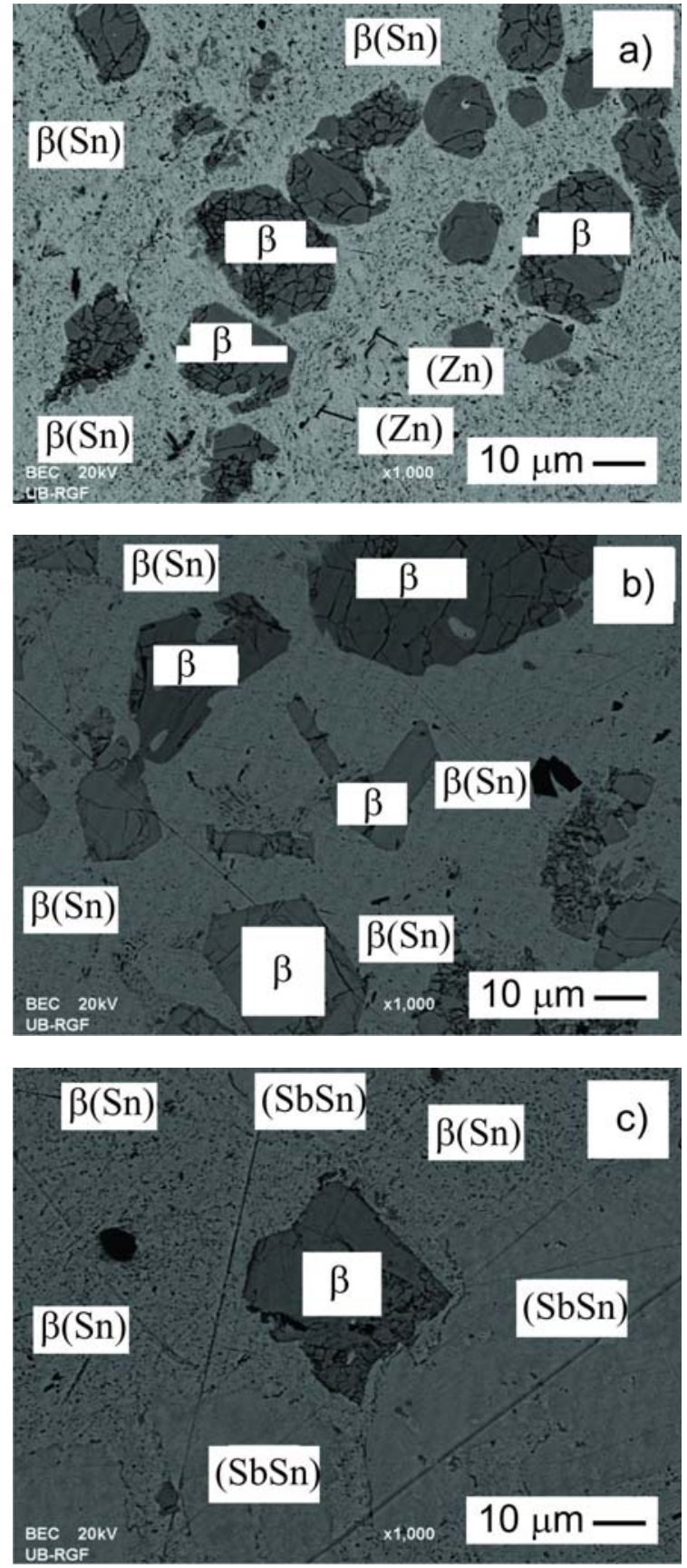

Fig. 4. SEM micrograph of the sample: (a) I $\left(\mathrm{Sb}_{3.97} \mathrm{Sn}_{80.08}\right.$ $\left.\mathrm{Zn}_{15.95}\right)$, (b) III (Sb10.04 $\left.\mathrm{Sn}_{8039} \mathrm{Zn}_{9.57}\right)$, and (c) VI (Sb ${ }_{17.57}$ $\left.\mathrm{Sn}_{80.52} \mathrm{Zn}_{1.91}\right)$. Composition in at.\%.

ture and predicted equilibria is found only for the samples I and II. Both samples I and II have the three-phase structure $((\mathrm{Sn})+\beta+(\mathrm{Zn}))$. The experimentally determined chemical composition of $\beta$ (SbZn) phase is significantly different (higher content of $\mathrm{Sb}$ ) from predicted one (Table 2). Microstructures of samples I and II include primary solidified crystals of $\beta(\mathrm{SbZn})$ phase and very small rod-like Zn-rich phase in the base of (Sn) phase (Fig. 4a).
Table 3. DTA results for the investigated alloys in the Sn-Sb-Zn ternary system

\begin{tabular}{|c|c|c|c|}
\hline \multirow{2}{*}{ Alloy } & \multirow{2}{*}{$\begin{array}{c}\text { Sample } \\
\text { composition } \\
(\text { at. } \%)\end{array}$} & \multicolumn{2}{|c|}{ Temperature $\left({ }^{\circ} \mathrm{C}\right)$} \\
\hline & & Other peaks & Liquidus \\
\hline I & $\begin{array}{c}\mathrm{Sn}=80.08 \\
\mathrm{Sb}=3.97 \\
\mathrm{Zn}=15.95\end{array}$ & 192 & 291 \\
\hline II & $\begin{array}{c}\mathrm{Sn}=80.31 \\
\mathrm{Sb}=7.97 \\
\mathrm{Zn}=11.72\end{array}$ & 199 & 308 \\
\hline III & $\begin{array}{c}\mathrm{Sn}=80.39 \\
\mathrm{Sb}=10.04 \\
\mathrm{Zn}=9.57\end{array}$ & 195 & 312 \\
\hline IV & $\begin{array}{c}\mathrm{Sn}=80.37 \\
\mathrm{Sb}=11.70 \\
\mathrm{Zn}=7.93\end{array}$ & 198,235 & 311 \\
\hline $\mathrm{V}$ & $\begin{array}{c}\mathrm{Sn}=80.38 \\
\mathrm{Sb}=14.13 \\
\mathrm{Zn}=5.49\end{array}$ & $180,230,253$ & 307 \\
\hline VI & $\begin{array}{c}\mathrm{Sn}=80.52 \\
\mathrm{Sb}=17.57 \\
\mathrm{Zn}=1.91\end{array}$ & 249 & 299 \\
\hline
\end{tabular}

The same observation was presented in references [16, 17].

Experimentally determined phase structures of samples III, IV, V, and VI are different from predicted phase equilibria. Beside predominant (Sn) solid solution phase the presence of ternary phase with the approximate chemical composition corresponding to the $\mathrm{Sb}_{5} \mathrm{Sn}_{3} \mathrm{Zn}_{2}$ compound was detected by SEM-EDS analysis.

Average chemical composition of recognized ternary compound in this study is close to the previously reported ternary compound $\mathrm{Sb}_{2} \mathrm{SnZn}$ [9].

Micrographs of samples III and VI with marked experimentally determined phases are shown in Fig. 4a and $4 \mathrm{c}$, respectively.

\subsection{Thermal properties}

Experimental determination of phase transition temperatures of the investigated samples was done using differential thermal analysis (DTA).

The phase transition temperatures were taken from peak maximum on heating. In the present DTA measurements, the thermocouple was immersed directly in the sample and because of that DTA signal corresponding to peak maximum was used for determina- 


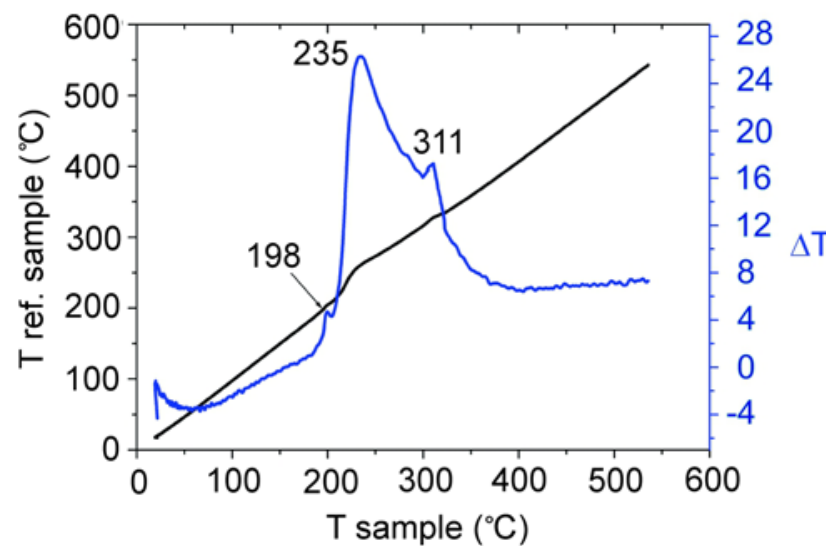

Fig. 5. DTA heating curve for the alloy sample IV $\left(\mathrm{Sb}_{11.07} \mathrm{Sn}_{80.37} \mathrm{Zn}_{7.93}\right.$ composition in at.\%) (conditions: argon atmosphere, sample mass $3 \mathrm{~g}$, heating rate 10 $\left.\mathrm{K} \min ^{-1}\right)$.

tion of phase transition temperatures. The accuracy of the given temperatures is $\pm 2{ }^{\circ} \mathrm{C}$.

The overall DTA results are given in Table 3.

Characteristic DTA heating curve for the sample IV with marked phase transition temperatures is given in Fig. 5.

Figure 6 represents DTA curve for the sample V. The registered peaks temperatures on heating are denoted in Fig. 6.

Experimentally determined phase transformation temperatures (DTA) together with the phase transition temperatures obtained using Scheil simulation (Fig. 3) are shown on calculated vertical section with 80 at.\% Sn (Fig. 7) for comparison.

As can be seen in Fig. 7 there is a very good agreement between liquidus temperatures obtained by DTA measurements, equilibrium phase diagram prediction and Scheil solidification simulation for all six investigated samples.

Also, there is a fair agreement between experimentally determined solidus temperatures, equilib-

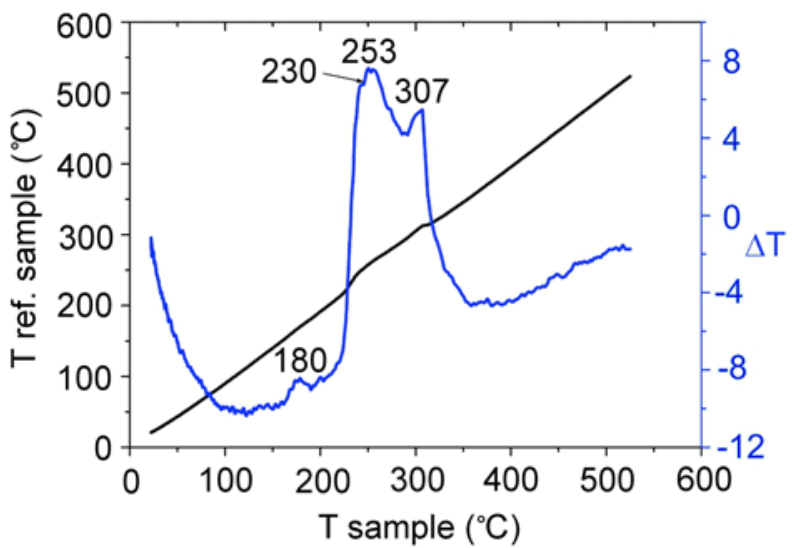

Fig. 6. DTA heating curve for the alloy sample V ( $\mathrm{Sb}_{14.13} \mathrm{Sn}_{80.38} \mathrm{Zn}_{5.49}$ composition in at.\%) (conditions: argon atmosphere, sample mass $3 \mathrm{~g}$, heating rate 10 $\left.\mathrm{K} \min ^{-1}\right)$.

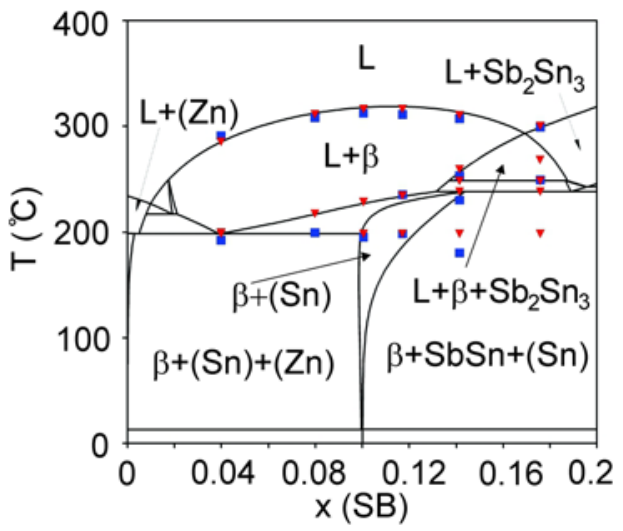

Fig. 7. Predicted vertical section of the Sn-Sb-Zn ternary system with 80 at.\% of Sn compared to the DTA results from this work and Scheil simulation. Temperatures measured by DTA on heating are denoted by blue squares. The red triangles represent predicted temperatures of phase transitions by Scheil simulations.

Table 4. Alloys and corresponding electrical conductivities

\begin{tabular}{cccccc}
\hline \multirow{2}{*}{ Alloy } & \multicolumn{4}{c}{ Electrical conductivity, $\sigma\left(\mathrm{MS} \mathrm{m}^{-1}\right)$} \\
\cline { 2 - 5 } & Ref. & Meas. 1 & Meas. 2 & Meas. 3 & Average value \\
\hline I & This work & 6.05 & 6.15 & 6.10 & 6.10 \\
II & This work & 5.88 & 5.71 & 5.81 & 5.80 \\
III & This work & 5.24 & 5.32 & 5.34 & 6.30 \\
IV & This work & 5.97 & 5.98 & 6.05 & 5.80 \\
V & This work & 5.77 & 5.77 & 5.86 & 5.30 \\
VI & This work & 5.29 & 5.32 & 5.29 & $5.52-5.95$ \\
Pb-5Sn & Ref. [2] & & & & \\
\hline
\end{tabular}


rium phase diagram calculation and Scheil solidification simulation for the samples I, II and III. According to calculated results solidus temperatures for samples I, II and III correspond to ternary eutectic reaction $\mathrm{L} \leftrightarrow \beta+(\mathrm{Sn})+(\mathrm{Zn})$ at calculated temperature $198^{\circ} \mathrm{C}$.

For samples IV, V, and VI, with higher content of $\mathrm{Sb}$ and lower content of $\mathrm{Zn}$, there are considerable differences between predicted equilibria, Scheil solidification simulation, and experimental results.

For the samples IV and V experimentally determined phase transition temperatures are in better agreement with Scheil solidification simulation results than the calculated phase diagram.

\subsection{Electrical conductivity measurements}

Electrical conductivity $(\sigma)$ of the investigated samples of the ternary Sn-Sb-Zn system was measured. Referring alloys and their electrical conductivities as well as the electrical conductivity of alloy $\mathrm{Pb}-5 \mathrm{Sn}$, are given in Table 4.

The results presented in Table 4 show that there are no significant differences between electrical conductivity of investigated alloys of the ternary Sn-Sb-Zn system and high-temperature $\mathrm{Pb}$-5Sn soldering alloy.

\section{Conclusions}

In this work six as-cast alloys with 80 at.\% of Sn and variable contents of $\mathrm{Sb}$ and $\mathrm{Zn}$ were experimentally investigated using scanning electron microscopy (SEM) with energy dispersive microanalysis (EDS) and differential thermal analysis (DTA).

Experimentally obtained results were compared with results of thermodynamic binary-based prediction of phase equilibria according to CALPHAD methodology and Scheil solidification simulations.

Only in the case of samples I, II, i.e. samples with low contents of $\mathrm{Sb}$, experimentally obtained results are in fair agreement with thermodynamic prediction results.

For the samples III, IV, V, and VI, with higher contents of $\mathrm{Sb}$, significant differences between thermodynamic prediction and experimental results were obtained.

Using SEM-EDS technique, the existence of ternary phase was identified in the microstructures of the as-cast samples III, IV, V, and VI. The stoichiometry of this experimentally determined ternary phase is approximately $\mathrm{Sb}_{5} \mathrm{Sn}_{3} \mathrm{Zn}_{2}$, which is close to those of the previously reported ternary compound $\mathrm{Sb}_{2} \mathrm{SnZn}[9]$.

The agreement between liquidus temperatures measured using DTA and thermodynamically predicted liquidus temperatures is very good for all in- vestigated samples. Also, experimentally determined solidus temperatures are close to the predicted temperature of ternary eutectic reaction $\mathrm{L} \leftrightarrow \beta+(\mathrm{Sn})+$ (Zn) at calculated temperature $198^{\circ} \mathrm{C}$.

For the samples IV and V, solidus temperatures differ significantly from predicted values and are generally in better agreement with the results of Scheil non-equilibrium solidification simulations.

Electroconductivity of investigated alloys is close to electroconductivity of high-temperature $\mathrm{Pb}-5 \mathrm{Sn}$ soldering alloy.

\section{Acknowledgements}

Calculations were performed by PANDAT 8.1 software. The authors acknowledge the support from the Ministry of Science of the Republic of Serbia (Project No. 172037).

\section{References}

[1] Chen, S. W., Chen, C. C., Gierlotka, W., Zi, A. R., Chen, P. Y., Wu, H. J.: J. Electron. Mater., 37, 2008, p. 992. doi:10.1007/s11664-008-0464-x

[2] Kim, J. H., Jeong, S. W., Lee, H. M.: Mater. Trans., 43, 2002, p. 1873 . doi: $10.2320 /$ matertrans. 43.1873

[3] Chen, S. W., Wang, C. H., Lin, S. K., Chiu, C. N.: J. Mater. Sci: Mater. Electron., 18, 2007, p. 19. doi:10.1007/s10854-006-9010-x

[4] Chen, S. W., Chen, P. Y., Wang, C. H.: J. Electron. Mater., 35, 2006, p. 1982. doi:10.1007/s11664-006-0303-x

[5] Corbin, S. F.: J. Electron. Mater., 34, 2005, p. 1016. doi:10.1007/s11664-005-0089-2

[6] Jang, J. W., Kim, P. G., Tu, K. N.: J. Mater. Res., 14, 1999, p. 3895. doi:10.1557/JMR.1999.0527

[7] Plevachuk, Yu., Sklyarchuk, V., Yakymovych, A., Svec, P., Janickovic, D., Illekova, E.: J Mater Sci: Mater Electron, 22, 2011, p. 631. doi:10.1007/s10854-010-0188-6

[8] Gancarz, T., Gasior, W.: J. Phase Equilib. Diff., 32, 2011, p. 398. doi:10.1007/s11669-011-9916-8

[9] Zobac, O., Sopousek, J., Bursik, J., Zemanova, A., Roupcova, P.: Metall. Mater. Trans. A, 45, 2014, p. 1181. doi:10.1007/s11661-013-2104-1

[10] Dinsdale AT (2002) SGTE Unary Database. Version 4.4. 2002. www.sgte.org

[11] Dinsdale, A. T., Kroupa, A., Vizdal, J., Vrestal, J., Watson, A., Zemanova, A.: COST 531 Database for Lead-Free Solders. Ver. 3.0. 2008.

[12] Lukas, H. L., Fries, S. G., Sundman, B.: Computational Thermodynamics: The Calphad Method. Cambridge, Cambridge University Press 2007.

[13] Pingfang, S., Sundman, B.: TCC ${ }^{\mathrm{TM}}$ Thermo-Calc Software User's Guide. Version N. Stockholm, Foundation of Computational Thermodynamics 2002.

[14] Chen, S. L., Zhang, F., Daniel, S., Xie, F. Y., Yan, X. Y., Chang, Y. A., Schmid-Fetzer, R., Oates, W. A.: JOM, 55, 2003, p. 48. doi:10.1007/s11837-003-0010-5

[15] Dinsdale, A. T., Watson, A., Kroupa, A., Vrestal, J., Zemanova, A., Vizdal, J. (Eds.): COST Action 531- 
-Atlas of Phase Diagrams for Lead-Free Solders. Vol. 1. Brussels, COST Office 2008.

[16] Chen, W. X., Xue, S., Wang, H., Hu, Y., Wang, J.: J. Mater. Sci: Mater. Electron., 21, 2010, p. 719. doi:10.1007/s10854-009-9984-2
[17] Chen, W. X., Xue, S. B., Wang, H., Wang, J. X., Han, Z. J., Gao, L. L.: J. Mater. Sci: Mater. Electron., 21, 2010, p. 461. doi:10.1007/s10854-009-9939-7 